\title{
Reliability, validity and cut-off score of the Chinese version of the panic disorder severity scale self-report form in patients with panic disorder
}

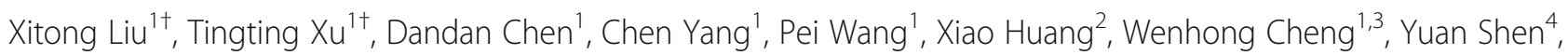
Qiang Liu ${ }^{1 *}$ and Zhen Wang ${ }^{1 *}$

\begin{abstract}
Background: Panic disorder (PD) is often undiagnosed, misdiagnosed, or untreated in non-psychiatric clinical settings. Therefore, a cost-effective, accurate and easy-to-administer instrument for PD assessment is still needed. For that reason, the self-report version of the Panic Disorder Severity Scale (PDSS-SR) has been developed and suggested to be a reliable and useful tool in clinical and research settings. The current study aims to evaluate the reliability and validity of the Chinese version of the PDSS-SR and determine the cut-off score of the PDSS-SR.

Methods: A total of 133 patients with PD in Shanghai were assessed by the PDSS-SR, PDSS and Hamilton Anxiety Rating Scale (HAMA). Moreover, 117 patients with non-PD anxiety and 51 healthy subjects also completed the PDSS-SR to construct a receiver operating characteristic (ROC) curve with the scores of PD patients.

Results: The internal consistency (Cronbach's a) of the PDSS-SR was 0.72-0.80, and the interrater correlation coefficient was 0.78 . The results of principal component analysis and varimax rotation indicated that the PDSS-SR had a two-factor structure, with all seven items having salient loadings. The cut-off score was 4, which was associated with high sensitivity (96.03\%) and specificity (61.31\%).

Conclusions: The findings demonstrate that these items and the total score of the PDSS-SR have acceptable reliability and validity in patients with PD and that the PDSS-SR can be used by general doctors for clinical screening in China.
\end{abstract}

Keywords: Panic disorder severity scale-self report, Reliability, Validity, Cut-off score

\section{Background}

Panic disorder (PD), a common psychiatric disorder, has a morbidity of $1.6-2.2 \%$ worldwide $[1,2]$. A meta-analysis of the prevalence of anxiety disorders in mainland China from 2000 to 2015 showed that the pooled prevalence of PD in

\footnotetext{
*Correspondence: speaks@139.com; wangzhen@smhc.org.cn

${ }^{\dagger}$ Xitong Liu and Tingting Xu are co-first authors.

'Shanghai Mental Health Center, Shanghai Jiao Tong University School of Medicine, No.600 South Wanping Road, Shanghai 200030, China

Full list of author information is available at the end of the article
}

China for current PD is $1.08 \%$ (95\% CI: $0.74-1.43$ ), and the lifetime prevalence is $3.44 \%$ ( $95 \%$ CI: $2.46-4.41)$. In addition, compared with females, males seem to have a lower risk of developing PD (current: $\mathrm{OR}=0.50,95 \% \mathrm{CI}$ : 0.32-0.77; lifetime: $\mathrm{OR}=0.49,95 \%$ CI: 0.33-0.72) [3]. Compared to healthy subjects, PD patients have higher unemployment rates, more significant work impairment, and a higher frequency of medical treatment and hospitalization [4], seriously affecting the normal life of the individual.

(c) The Author(s). 2020 Open Access This article is licensed under a Creative Commons Attribution 4.0 International License, which permits use, sharing, adaptation, distribution and reproduction in any medium or format, as long as you give appropriate credit to the original author(s) and the source, provide a link to the Creative Commons licence, and indicate if changes were made. The images or other third party material in this article are included in the article's Creative Commons licence, unless indicated otherwise in a credit line to the material. If material is not included in the article's Creative Commons licence and your intended use is not permitted by statutory regulation or exceeds the permitted use, you will need to obtain permission directly from the copyright holder. To view a copy of this licence, visit http://creativecommons.org/licenses/by/4.0/ The Creative Commons Public Domain Dedication waiver (http://creativecommons.org/publicdomain/zero/1.0/) applies to the data made available in this article, unless otherwise stated in a credit line to the data. 
Thus, more research is needed regarding the origins and treatment of PD.

The typical symptoms of PD include unexpected and recurrent panic attacks and the corresponding consequences. PD patients have an increased risk of comorbid psychosis, manic behaviour, drug abuse, depression, dysthymia and suicide. Although several effective treatments are now available, as many as half of individuals with PD are undiagnosed, misdiagnosed, or untreated $[1,5,6]$, which makes it necessary to make an effort to better understand PD.

A considerable proportion of PD patients are initially diagnosed by general physicians or emergency physicians [1]. In the cardiology department, 38 to $47.1 \%$ of patients with the chief complaint of chest pain suffer from PD $[7,8]$. Due to their cardiovascular and neurological symptoms, patients with PD can easily be misdiagnosed with somatic diseases, and their initial visits are often in the cardiology, emergency and neurology department $[3,9]$. In Fleet's study, 441 PD patients with chest pain as a chief complaint went to the emergency department for treatment; only $2 \%$ of subjects were diagnosed with PD $[1,10]$. The low diagnosis rate seriously influences the early treatment of PD and results in heavy social and economic burdens $[2,11]$.

A screening tool is required for the general hospital, especially in cardiology and emergency departments, to help physicians recognize common symptoms of PD. For PD scales, such as the Panic and Agoraphobia Scale (PAS) and the Albany Panic and Phobic Questionnaire (APPQ), only the Panic Disorder Severity Scale (PDSS) and the Panic-Associated Symptom Scale (PASS) have been tested by Chinese researchers [12]. The PASS was published in 1991 when it was used to assess the core symptoms of PD in the DSM-III-R. The PDSS, a scale intended for determining severity in individuals already diagnosed with PD, is effectively utilized for the assessment, prevention, and intervention phases of PD. However, it is costly and time-consuming to train general doctors to use the PDSS [3, 13]. Hence, a cost-effective, accurate, and easy-to-administer measure for PD is still needed. For that reason, the Panic Disorder Severity Scale-Self Report (PDSS-SR) was developed as a selfreported version of the PDSS [14] to rate the overall severity of PD [5]. The PDSS-SR consists of 7 items coded on a 5-point ordinal scale (0-4), in which higher scores indicate a more severe panic attack. The PDSS-SR can be performed by patients without the help of trained physicians or interviewers. Thus, this scale is easily used for the screening of PD in general hospitals.

The cut-off score can be utilized to distinguish PD patients from non-PD patients; thus, this score may be useful as a tool to screen patients in settings such as primary care for diagnosis-related symptoms [15]. However, only one study has proposed a cut-off score worldwide, reflecting a challenge for clinical work [16]. Although many clinicians and researchers have applied the PDSS-SR in their work, there is still ambiguity regarding the diagnostic threshold of PD in China. Thus, the present study had two major aims: 1) to test the reliability and validity of the Chinese version of the PDSS-SR and 2) to determine an optimal cut-off score for the PDSS-SR.

\section{Methods \\ Participants}

A total of 133 PD patients (74 females and 58 males, one person unknown) from four hospitals (Shanghai Mental Health Center, Shanghai First People's Hospital, Shanghai Tenth People's Hospital and Zhongshan Hospital) were enrolled from October 2017 to March 2018. A total of 117 non-PD patients with other anxiety disorders and 51 healthy controls $(\mathrm{HCs})$ were also included. All subjects aged 18-65 years provided informed consent and participated voluntarily. PD patients and non-PD patients were all diagnosed by the chief physician of psychiatry according to the ICD-10. The exclusion criteria were as follows: 1 ) concurrent diagnosis or past history of any other psychiatric disorder; 2) pregnancy or $\leq 6$ months postpartum; 3 ) inability to read and understand the informed consent form or self-reported questionnaires; and 4) presentation with acute suicidality. This study was approved by the ethics committee of the Shanghai Mental Health Center.

\section{Measures and procedures}

The PDSS-SR, a new self-report diagnostic measure of PD adapted from the PDSS, can be used by patients to monitor the severity of their symptoms in the last week. The PDSS-SR has seven items that can assess patients' panic attack frequency, distress during panic attack, anticipatory anxiety, agoraphobic fear/avoidance, fear/ avoidance of panic-related bodily sensations, work impairment and social impairment based on their rating on a five-point scale $(0=$ "not at all" to $4=$ "most severe"). Item ratings are summed to form the total score, with higher scores indicating greater symptom severity.

The adopted PDSS is the Chinese version that has been clinically tested with good reliability and validity and better diagnostic efficiency for PD. The PDSS is a seven-item scale designed to assess the overall severity of PD symptoms by a psychiatrist or trained interviewer.

Another assessment instrument, the Hamilton Anxiety Scale (HAMA), which is a 14-item measure rated on a five-point scale $(0=$ "not at all" to $4=$ "most severe"), is widely utilized in clinical symptom evaluation for assessing the severity of emotional and physical anxiety [17].

This study is a multicentre study with a number of patients recruited from the psychology departments of four hospitals. General demographics, disease information, PDSS and HAMA were assessed by a unified trained 
clinical researcher. Participants completed the selfreport measures by themselves. Two weeks later, the PDSS-SR was again assessed.

\section{Statistical analyses}

All analyses were conducted using SPSS 20.0. Internal consistency of the PDSS-SR was evaluated using Cronbach's $\alpha$. Test-retest reliability was examined using Pearson correlations between session one and session two scores (2 weeks later). Parallel validity was evaluated with Pearson correlations between the PDSS-SR (total and item scores) and the different instruments administered (PDSS and HAMA). The baseline structural validity was evaluated by exploratory factor analysis. The cut-off score was determined by performing receiver operating characteristic curve (ROC) analysis.

\section{Results}

\section{Demographic properties}

The mean age of the total PD sample $(n=133)$ was $37 \pm$ 12 years. The age range in our study was $18-60$ years. A total of $55.6 \%$ of the sample was female. The mean duration of the disorder (in months) was $8(2,24)$ for the whole group and the retest sample. Table 1 displays the socio-demographic properties of the different groups.

We also compared the PD, non-PD anxiety and healthy groups according to age, sex, education and the PDSS-SR score using the Chi-square test. The results are shown below (Table 2).

\section{Reliability}

\section{Internal consistency reliability}

Cronbach's $\alpha$ of the PDSS-SR was 0.78, which indicated the high reliability of this scale, and the Cronbach's $\alpha$ of each item with the sum of the remaining items (if the item was deleted) is shown in Table 2. For the whole group $(n=133)$, the items of work impairment and social impairment showed a high correlation $(0.65$ and 0.63 , respectively), while the item of distress during panic attacks showed a low correlation (0.34).

Table 1 Sample characteristics

\begin{tabular}{|c|c|c|c|}
\hline & & $\begin{array}{l}\text { Whole sample } \\
(N=133)\end{array}$ & $\begin{array}{l}\text { Test-retest sample } \\
(N=74)\end{array}$ \\
\hline \multicolumn{2}{|c|}{ Age (M, SD, year) } & $37(12)$ & $38(12)$ \\
\hline \multirow[t]{2}{*}{ Gender } & Male & 58 & 36 \\
\hline & Female & 74 & 38 \\
\hline \multicolumn{2}{|c|}{ Education level (M,SD) } & 14(3) & 14(3) \\
\hline \multicolumn{2}{|c|}{ Illness duration (Months) } & $8(2,24)$ & $8(2,24)$ \\
\hline \multicolumn{2}{|c|}{ PDSS-SR score } & $10.53(4.56)$ & $5.68(3.67)$ \\
\hline
\end{tabular}

Annotation: one patient default

\section{Test-retest reliability}

For the group of panic disorder patients who were reassessed after 2 weeks, the Pearson correlation coefficient $\left(r^{2}\right)$ between the PDSS-SR scores at baseline and after 2 weeks was 0.42 , which reached statistical significance, and the correlation of each item was between 0.13 and 0.37 (Table 3).

\section{Validity \\ Factor analysis}

According to the appropriate tests, we obtained a Kaiser-Meyer-Olkin of 0.75 , and the $\chi^{2}$ from Barlett's test was $281.03(p<0.001)$, which was suitable for performing factor analysis. After the principal component analysis (PCA), a model with two correlated factors was constructed, with the first of the three items (i.e., the symptoms of panic attack) loading on the second factor (panic attacks factor, focuses on physical symptoms), and the other four on the first factor. These two factors with eigenvalues $>1$ could explain $60.59 \%$ of the total variance. The rotated component matrix is shown in Table 4.

\section{Parallel validity}

Regarding the correlations of measures from baseline, the Pearson correlation coefficient, $r$, for the PDSS-SR total score was 0.68 with the PDSS and 0.42 with the HAMA, and they were both statistically significant $(p<$ $0.001)$.

\section{Cut-off score}

A total of 117 patients without panic disorders but with other anxiety disorders and 51 healthy subjects were tested using the PDSS-SR, and ROC curves were plotted with data from patients with PD. When the Jordan index calculated from the curve coordinates was 0.5734 , we obtained the optimal sensitivity (96.03\%) and specificity (61.31\%), and it can be determined that the corresponding demarcation is divided into 4 points. The area under the curve (AUC) was 0.782 (S.E. $=0.03, p<0.001$ ), indicating that the scale has certain diagnostic accuracy (Fig. 1).

\section{Discussion}

Panic disorder is a kind of anxiety disorder with autonomic nervous dysfunction as the main symptom. Patients often go to various general hospitals for physical examination instead of mental health centres in the first stage. This study aimed to assess the reliability and validity of the Chinese version of the PDSS-SR to show that it can be widely used as an ideal tool for outpatients in general hospitals. We also determined the cut-off score to improve the diagnostic effect of the scale. The results demonstrate that these items and the total score of the 
Table 2 Chi-square test between three groups

\begin{tabular}{|c|c|c|c|c|c|c|}
\hline & & $\mathrm{PD}(n=133)$ & Non-PD anxiety $(n=117)$ & $\mathrm{HC}(n=51)$ & $\mathrm{F}$ & $p$ \\
\hline Age & & $37(12)$ & $36(13)$ & $33(8)$ & 118.98 & 0.095 \\
\hline \multirow[t]{2}{*}{ Gender } & Male & 58 & 49 & 20 & 0.35 & 0.838 \\
\hline & Female & 74 & 68 & 31 & & \\
\hline Education & & 13.83(3.19) & $12.99(3.61)$ & $14.39(2.21)$ & 45.99 & 0.052 \\
\hline PDSS-SR & & $10.49(4.58)$ & $6.58(6.11)$ & $0.43(1.15)$ & 201.82 & $0.000^{* *}$ \\
\hline
\end{tabular}

PDSS-SR had acceptable reliability and validity over a two-week period in patients with PD, which is similar to the findings of a previous multicentre study [12]. The cut-off score was 4 , which was associated with high sensitivity and ideal specificity.

We found that when the cut-off was 4, the AUC was 0.783 , showing that the effectiveness of this model in detecting PD was acceptable. The PDSS-SR was found to have a high sensitivity of $96.03 \%$, which meant that people with PD only had a $3.97 \%$ chance of being missed, and most patients could be identified and diagnosed. However, the specificity was $61.31 \%$, indicating that the false positive rate for this score was $38.69 \%$, which meant there was a $38.69 \%$ chance that patients will be misdiagnosed. Compared with the previous study in which the cut-off was 8.5 (with $89 \%$ sensitivity and $100 \%$ specificity) [16], our research obtained a lower specificity based on the 4-point cut-off, which may be influenced by cultural differences between the East and the West. Nevertheless, we restricted the PD participants and excluded patients with comorbidities and obtained a higher sensitivity, which is more important for screening scales, especially for nonpsychiatric departments in general hospitals. Patients with suspected panic disorder may be referred to psychiatric departments for further diagnosis and treatment, where false positives are partially offset.

Table 3 Statistical results of internal consistency

\begin{tabular}{llll}
\hline Items & $\begin{array}{l}\text { Alpha if } \\
\text { item-deleted }\end{array}$ & $\begin{array}{l}\text { Corrected } \\
\text { item-total } \\
\text { correlation } \\
\text { r1 }\end{array}$ & $\begin{array}{l}\text { Corrected } \\
\text { item-total } \\
\text { correlation } \\
\text { r2 }\end{array}$ \\
\hline Panic attack frequency & 0.76 & 0.45 & 0.22 \\
Distress during panic attacks & 0.80 & 0.34 & 0.13 \\
Severity of anticipatory anxiety & 0.75 & 0.52 & $0.37^{* *}$ \\
Agoraphobic fear/avoidance & 0.75 & 0.53 & $0.34^{* *}$ \\
Panic related sensation fear/ & 0.75 & 0.52 & $0.29^{* *}$ \\
avoidance & & & $0.35^{* *}$ \\
Work impairment & 0.72 & 0.65 & $0.33^{* *}$ \\
Social impairment & 0.73 & 0.63 &
\end{tabular}

Note: ** Correlation is significant at the 0.01 level (2-tailed)
The test-retest reliability was 0.42 , and the correlations of each item were between 0.13 and 0.37 . The reliability coefficient of the retest was lower than those obtained in previous studies [12, 13], whose intervals were quite short (1-5 days) after the initial test. The retest interval of this study was 2 weeks, during which the characteristics measured by the scale may have changed. Within 2 weeks, most patients were treated with SSRIs; thus, improvement in symptoms may have affected this indicator. In conclusion, the low retest reliability does not indicate poor PDSS-SR reliability.

We used factor analysis to determine construct validity and separated out 2 factors. The interpretable variance was $60.59 \%$. Items $1-3$ loaded on the first factor, and the other 4 items loaded on the second factor. Although the result was inconsistent with the previous one-factor model of PDSS-SR [13], it was consistent with the twofactor structure of PDSS and the general features of panic disorder, to be specific, cognitive components (i.e., expectation anxiety, phobic features), physical components and anxiety, even if the entries under the factor were different from those of previous studies $[18,19]$.

Although many psychometric properties of the PDSSSR were reported in detail and the cut-off value of panic disorder was calculated, some limitations should also be considered. First, the specificity was lower than that in a previous study, which would lead to increased misdiagnosis and, to some extent, increase the cost of medical treatment for people. Second, we did not consistently control the patients' treatment during the 2-week interval. Although most patients were treated with SSRIs, some

Table 4 Rotated component matrix

\begin{tabular}{lll}
\hline Items & Factor 1 & Factor 2 \\
\hline Panic attack frequency & 0.18 & 0.74 \\
Distress during panic attacks & 0.02 & 0.76 \\
Severity of anticipatory anxiety & 0.46 & 0.49 \\
Agoraphobic fear/avoidance & 0.81 & 0.08 \\
Panic related sensation fear/ avoidance & 0.85 & 0.02 \\
Work impairment & 0.65 & 0.46 \\
Social impairment & 0.67 & 0.41 \\
\hline
\end{tabular}




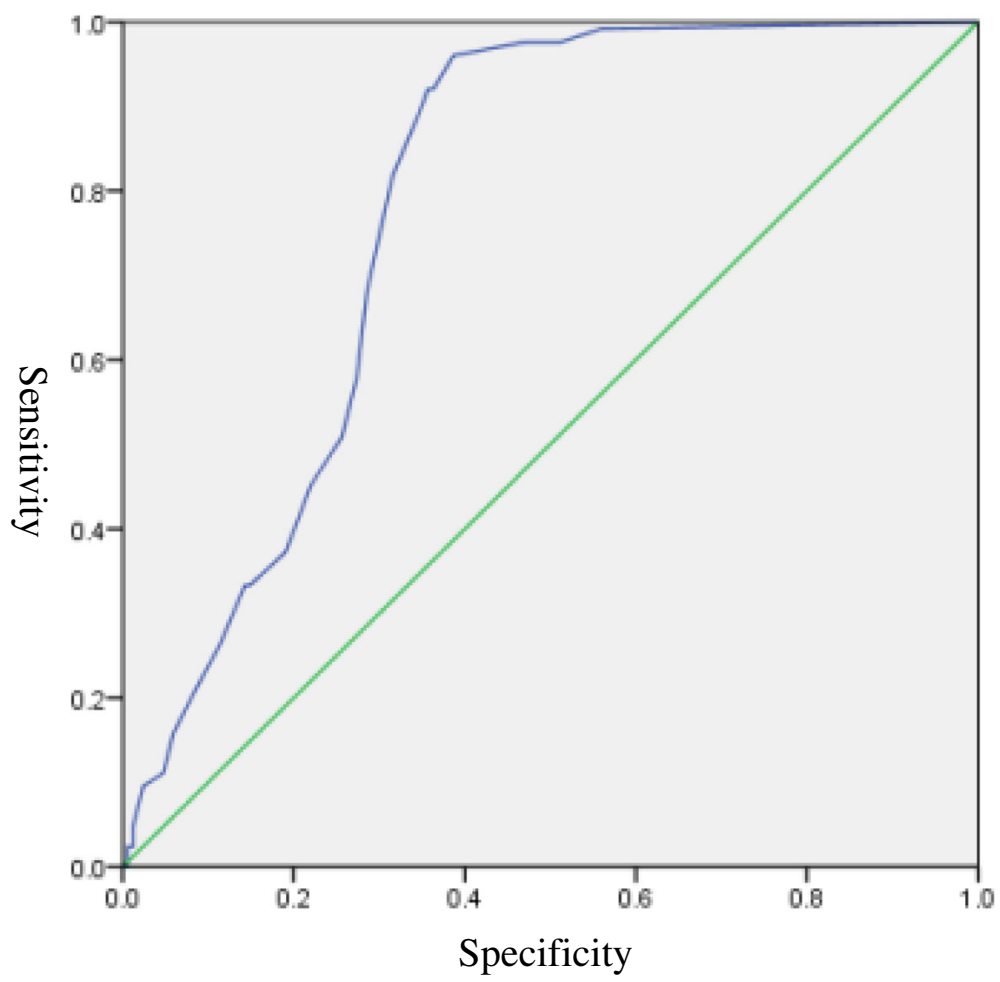

Fig. 1 Receiver-operating characteristic curve (ROC) analysis of the PDSS-SR

patients received no treatment, which may have affected the retest reliability.

\section{Conclusion}

In conclusion, our study calculated a new and reasonable cut-off for the Chinese version of the PDSS-SR and confirmed that it is a tool with acceptable reliability and validity over a two-week period in patients with $\mathrm{PD}$, demonstrating its convenience for the clinical screening of PD, especially in general hospitals.

\section{Abbreviations}

PD: Panic disorder; PDSS: Panic Disorder Severity Scale; PDSS-SR: Panic Disorder Severity Scale Self-Report; HC: Healthy control; HAMA: Hamilton Anxiety Scale; ROC: Receiver-operating characteristic curve; PCA: Principal component analysis; AUC: Area under the curve

\section{Acknowledgements}

Not Applicable

\section{Authors' contributions}

$\mathrm{XL}$ and TX led the design, data collection and analysis and article writing. They contributed equally to this work and should be considered co-first authors. ZW contributed to the design and general scheduling. QL was responsible for the design and arrangement of data collection in Shanghai Mental Health Center. ZW and QL were both corresponding authors. CY, PW and DC assisted with data collection and language polishing. XH, WC and YS were responsible for the arrangement of data collection in their respective general hospitals. All authors read and approved the final version of the manuscript.

\section{Funding}

This work was funded by Shanghai Municipal Education Commission-Gao Feng Clinical Medicine Grant [grant numbers 20161321] and the Municipal Human Resources Development Program for Outstanding Leaders in Medical Disciplines in Shanghai [grant number 2017BR058]. The above funds were provided by Shanghai Municipal Government and supported data collection, article writing and publication of this study.

\section{Availability of data and materials}

The datasets used and/or analysed during the current study are available from the corresponding author on reasonable request.

\section{Ethics approval and consent to participate}

Ethical approval for this study was granted by the Institutional Review Board (IRB) of Shanghai Mental Health Center. Participants were aged 18 years or above, and all of them signed full informed consent forms, as requested by the IRB.

\section{Consent for publication}

Not Applicable

\section{Competing interests}

The authors declare that they have no competing interests.

\section{Author details}

${ }^{1}$ Shanghai Mental Health Center, Shanghai Jiao Tong University School of Medicine, No.600 South Wanping Road, Shanghai 200030, China.

${ }^{2}$ Department of Psychological Medicine, Zhongshan Hospital, Fudan University, No.180 Fenglin Road, Shanghai 200032, China. '3epartment of Medical Psychology, Shanghai General Hospital, Shanghai Jiao Tong University School of Medicine, No. 100 Haining Road, Shanghai 200080, China. ${ }^{4}$ Department of Psychiatry, Tenth People's Hospital of Tongji University, No.301 Middle Yanchang Road, Shanghai 200072, China. 
Received: 11 December 2019 Accepted: 23 March 2020

Published online: 15 April 2020

\section{References}

1. Esan $\mathrm{OB}$, Baiyewu O. Panic disorder prevalence among patients referred for an electrocardiogram in a Nigerian teaching hospital. Psychosomatics. 2013; 54(5):472-8

2. Freire RC, Hallak JE, Crippa JA, Nardi AE. New treatment options for panic disorder: clinical trials from 2000 to 2010. Expert Opin Pharmacother. 2011; 12(9):1419-28.

3. Guo X, Meng Z, Huang G, Fan J, Zhou W, Ling W, et al. Meta-analysis of the prevalence of anxiety disorders in mainland China from 2000 to 2015. Sci Rep. 2016;6:28033.

4. Bystritsky A, Kerwin L, Niv N, Natoli JL, Klap NAR, Kenneth Wells ASY. Clinical and subthreshold panic disorder. Depress Anxiety. 2010;27(4):381-9.

5. Houck PR, Spiegel DA, Shear MK, Rucci P. Reliability of the self-report version of the panic disorder severity scale. Depress Anxiety. 2002;15(4):183-5.

6. Jeejeebhoy FM, Dorian P, Newman DM. Panic disorder and the heart : a cardiology perspective. J Psychosom Res. 2000;48(4-5):393-403.

7. Bringager CB, Gauer K, Arnesen H, Friis S, Dammen T. Nonfearful panic disorder in chest-pain patients: status after nine-year follow-up. Psychosomatics. 2008:49(5):426-37.

8. Hocaoglu C, Gulec MY, Durmus I. Psychiatric comorbidity in patients with chest pain without a cardiac etiology. Isr J Psychiatry Relat Sci. 2008:45(1):49-54.

9. Zhang BW, Xu J, Chang Y, Wang H, Yao H, Tang D. Impaired cognitive reappraisal in panic disorder revealed by the late positive potential. Neuroreport. 2016;27(2):99-103.

10. Fleet RP, Dupuis G, Marchand A, Burelle D, Arsenault A, Beitman BD. Panic disorder in emergency department chest pain patients: prevalence, comorbidity, suicidal ideation, and physician recognition. Am J Med. 1996; 101(4):371-80.

11. Olesen J, Gustavsson A, Svensson M, Wittchen HU, Jönsson B. The economic cost of brain disorders in Europe. Eur J Neurol. 2012;19(1):155-62.

12. $\mathrm{YL} \mathrm{HE}$, et al. Reliability and validity of the Chinese version of panic disorder severity scale and panic-associated symptom scale. Chin J Psychiatry. 2013; 46(4):217-22.

13. Lee E, Kim J, Yu B. Reliability and validity of the self-report version of the panic disorder severity scale in Korea. Depress Anxiety. 2009;26(8):E120-3.

14. Shear MK, Brown TA, Barlow DH, Money R, Sholomskas DE, Woods SW, et al. Multicenter collaborative panic disorder severity scale. Am.J Psychiatry. 1997; 154(11):1571-5.

15. Shear MK, Rucci P, Williams J, Frank E, Grochocinski V, Bilt J. Vander, et al. reliability and validity of the panic disorder severity scale: replication and extension. J Psychiatr Res. 2001;35(5):293-6.

16. Newman MG, Holmes M, Zuellig AR, Kachin KE, Behar E. The reliability and validity of the panic disorder self-report: a new diagnostic screening measure of panic disorder. Psychol Assess. 2006;18(1):49-61.

17. Hamilton M. The assessment of anxiety states by rating. Br J Med Psychol. 1959:32(1):50-5

18. Monkul ES, Tural Ü, Onur E, Fidaner H, Alkin T, Shear MK. Panic disorder severity scale: reliability and validity of the Turkish version. Depress Anxiety. 2004;20(1):8-16.

19. Fuste G, Gil MÁ, López-Solà C, Rosado S, Bonillo A, Pailhez G, et al. Psychometric properties of the Spanish version of the panic disorder severity scale. Span J Psychol. 2018;21:E5.

\section{Publisher's Note}

Springer Nature remains neutral with regard to jurisdictional claims in published maps and institutional affiliations.

Ready to submit your research? Choose BMC and benefit from:

- fast, convenient online submission

- thorough peer review by experienced researchers in your field

- rapid publication on acceptance

- support for research data, including large and complex data types

- gold Open Access which fosters wider collaboration and increased citations

- maximum visibility for your research: over $100 \mathrm{M}$ website views per year

At $\mathrm{BMC}$, research is always in progress.

Learn more biomedcentral.com/submissions 